\title{
Desafios e Reordenamentos do Processo de Trabalho na Rede Municipal de Ensino de Canoinhas-SC: Formação e Práticas para Enfrentamento da Pandemia pela Covid-19
}

\author{
Challenges and Reordering of the Work Process in the Municipal Schooling Network of \\ Canoinhas-SC: Training and Practices for Coping with the Pandemic by Covid-19

\begin{abstract}
Desafíos y reordenación del proceso de trabajo en la Red escolar municipal de Canoinhas-SC: capacitación y prácticas para hacer frente a la pandemia por Covid-19
\end{abstract} \\ Karina Vieira Carvalho ${ }^{1}$ \\ Maria Luiza Milani² \\ Argos Gumbowsky ${ }^{3}$
}

\section{Resumo}

O texto descreve os desafios, a mobilização, as decisões e a execução de medidas, ações e estratégias para o enfrentamento da suspensão das atividades educacionais presenciais na rede pública municipal de ensino do município de Canoinhas, estado de Santa Catarina decorrente da pandemia COVID-19. O estudo desenvolveu-se pelo método descritivo, com procedimentos de coletas de dados documentais e bibliográficos. Analisou-se sob a perspectiva processual das decisões e encaminhamentos realizados. $\mathrm{O}$ cenário pandêmico apresentado no início do ano letivo de 2020, representou uma barreira importante no fluxo do processo de ensino aos gestores, educadores, equipes técnicas e pedagógicas, que obrigatoriamente atuaram na reorganização dos programas suplementares educacionais de alimentação escolar, gestão, administração educacional e da assistência aos estudantes. A participação das instâncias de regulamentação e controle social, da política educacional do município, do estado e a assessoria de entidade representativa dos municípios associados na região, a Associação dos Municípios do Planalto Norte (AMPLANORTE), foi fundamental para que a interrupção das atividades educacionais presenciais não representasse uma ameaça ao direito de ensino e aprendizado. Considera-se que os desdobramentos a partir de estudos, discussões, permitiram de alguma forma, o planejamento e aprendizagens de novas formas de ensinar e aprender. A prática pedagógica desenvolvida de forma remota tornou-se realidade. As metodologias foram modificadas, a tecnologia tornou-se aliada no cotidiano escolar o que permitiu garantir o direito fundamental de acesso à educação por crianças, adolescentes, jovens e adultos do município de Canoinhas.

${ }^{1}$ Mestranda no Programa de Mestrado em Desenvolvimento Regional, Universidade do Contestado-UnC. Assistente Social da Secretaria Municipal de Educação de Canoinhas. E-mail: karina_vieiracarvalho@ hotmail.com ORCID: https://orcid.org/0000-0001-7266-2757

2Doutora em Serviço Social, Pontifícia Universidade Católica de São Paulo-PUCSP. Docente do Programa de Mestrado em Desenvolvimento Regional, Universidade do Contestado-UnC. Canoinhas-SC. E-mail: marialuiza@uc.br ORCID: https://orcid.org/0000-0001-7588-9324

3Doutor em Educação. Universidade Federal do Rio Grande do Sul-UFRGS. ocente do Programa de Mestrado em Desenvolvimento Regional, Universidade do Contestado-UnC. Canoinhas-SC. E-mail: $\underline{\arg g o s @ u c c . b r}$ ORCID: https://orcid.org/0000-0002-7217-9025 
Palavras-Chave: Educação. Ensino Fundamental. Pandemia. Reorganização Pedagógica. Ensino remoto.

\begin{abstract}
The text describes the challenges, mobilization, decisions and implementation of measures, actions and strategies to cope with the suspension of face-to-face educational activities in the municipal public school system of the municipality of Canoinhas, state of Santa Catarina resulting from the COVID-19 pandemic. The study was developed by descriptive method, with procedures for collecting documentary and bibliographic data. It was analyzed from the procedural perspective of the decisions and referrals made. The pandemic scenario presented at the beginning of the 2020 school year represented an important barrier in the flow of the teaching process to managers, educators, technical and pedagogical teams, who mandatorily acted in the reorganization of supplementary educational programs of school feeding, management, educational administration and student care. The participation of the bodies of regulation and social control, the educational policy of the municipality, the state and the advice of a representative entity of the associated municipalities in the region, the Association of Municipalities of planalto Norte (AMPLANORTE), was fundamental so that the interruption of face-to-face educational activities did not represent a threat to the right of teaching and learning. It is considered that the developments from studies, discussions, allowed in some way, the planning and learning of new ways of teaching and learning. The pedagogical practice developed remotely became reality. The methodologies were modified, technology became allied in daily school life, which allowed ensuring the fundamental right of access to education by children, adolescents, young people and adults in the municipality of Canoinhas.
\end{abstract}

Keywords: Education. Elementary school. pandemic. Pedagogical Reorganization. Remote teaching.

\title{
Resumen
}

El texto describe los desafíos, movilización, decisiones e implementación de medidas, acciones y estrategias para hacer frente a la suspensión de las actividades educativas presenciales en el sistema de escuelas públicas municipales del municipio de Canoinhas, estado de Santa Catarina como resultado de la pandemia de COVID-19. El estudio se desarrolló por método descriptivo, con procedimientos de recolección de datos documentales y bibliográficos. Se analizó desde la perspectiva procesal de las decisiones y remisiones realizadas. El escenario de pandemia presentado al inicio del año escolar 2020 representó una barrera importante en el flujo del proceso de enseñanza a directivos, educadores, equipos técnicos y pedagógicos, quienes actuaron obligatoriamente en la reorganización de los programas educativos complementarios de alimentación escolar, gestión, administración educativa y atención estudiantil. La participación de los órganos de regulación y control social, la política educativa del municipio, el estado y la asesoría de una entidad representativa de los municipios asociados en la región, la Asociación de Municipios de Planalto Norte (AMPLANORTE), fue fundamental para que la interrupción de las actividades educativas presenciales no representara una amenaza para el derecho de enseñanza y aprendizaje. Se considera que los desarrollos de los estudios, discusiones, permitieron de alguna manera, la planificación y el aprendizaje de nuevas formas de enseñanza y aprendizaje. 


\section{OO DEVIR EDUCAÇÃO}

ISSN: 2526-849X

La práctica pedagógica desarrollada a distancia se convirtió en realidad. Se modificaron las metodologías, la tecnología se alió en la vida escolar cotidiana, lo que permitió garantizar el derecho fundamental de acceso a la educación por parte de niños, adolescentes, jóvenes y adultos en el municipio de Canoinhas.

Palabras clave: Educación. escuela primaria. Pandemia. Reorganización Pedagógica. Enseñanza remota.

\section{Introdução}

O texto aborda as demandas apresentadas à rede pública municipal de ensino de Canoinhas, estado de Santa Catarina e os reordenamentos no processo de trabalho tanto da gestão do sistema educacional quanto na formação e práticas para o enfrentamento da pandemia decorrente da COVID-19.

Com a pandemia houve risco de colapso social e de contágio da comunidade escolar. Para mitigar a disseminação da doença, as aulas e outras atividades educacionais com atendimento presencial foram suspensas em todo o território nacional. Havia um acelerado avanço da contaminação com aumento de mortes e eram inexistentes quaisquer evidências ou estudos que fundamentassem o retorno seguro dos estudantes e trabalhadores da educação.

A problemática que envolvia o isolamento estava posta, tanto para a gestão quanto para os educadores e demais profissionais envolvidos na operacionalização da política educacional, bem como para os estudantes. Surgia a necessidade de encontrar alternativas para que os estudantes mantivessem o aprendizado nas etapas escolares e estratégias que viabilizassem o retorno das atividades o mais breve possível ainda no ano letivo de 2020 .

Sob esses aspectos, este artigo definiu como objetivo, expor as estratégias adotadas pela rede pública municipal de ensino de Canoinhas-SC e seus reordenamentos no processo de trabalho da gestão administrativa e pedagógica do sistema educacional, na formação continuada e práticas para o enfrentamento dos desdobramentos da crise sanitária em consequência da pandemia pela COVID-19.

O texto se constitui em um estudo descritivo, com o relato da experiência processual da organização de grupos de estudo e trabalho, da atuação dos diferentes setores da Secretaria Municipal de Educação e dos professores da rede pública municipal, dos cursos de formação para uso de tecnologias digitais de informação e comunicação (TDIC) e da definição de novas atribuições aos profissionais relacionados com a regulamentação e as justificativas das decisões nesse processo.

Revista Devir Educação, Lavras-MG. Edição Especial, p.341-362, Set./2021. 
$\mathrm{Na}$ abordagem deste artigo se considera a atuação administrativa e pedagógica da rede pública municipal de ensino analisados, focalizando a agilidade de reorganização apesar das especificidades da política educacional do município para a manutenção do direito à educação dos cidadãos canoinhenses no ano letivo iniciado em 2020.

Apresentam-se apontamentos acerca da pandemia provocada pela COVID-19, as medidas gerais de combate à crise sanitária pelo governo brasileiro. Em seguida são apresentadas as discussões e alternativas à suspensão das aulas e revisão das atribuições dos profissionais e das rotinas de trabalho para a implementação das atividades educacionais não presenciais e a formação dos professores.

\section{Implicações da Covid-19 no Cotidiano Social}

A Organização Mundial de Saúde (OMS) declarou Emergência de Saúde Pública de Interesse Internacional $^{1}$, em janeiro de 2020, devido ao surto da infecção pela COVID-19, com registros de casos de contágio em aproximadamente $100^{2}$ países e a ocorrência de mortes que aumentava cotidianamente.

O Brasil considerou os alertas da OMS e declarou a emergência de saúde pública em fevereiro e em março de 2020 reconheceu o estado de calamidade pública. Com esta declaração ocorreu revisão das prioridades do sistema público de saúde para torná-lo mais ágil no diagnóstico, tratamento da doença e no incremento de ações de educação comunitária, divulgando práticas sanitárias preventivas contra a infecção. Uma das principais estratégias para a contenção da disseminação da COVID-19 no Brasil, foi a adoção de medidas de isolamento social legalizadas pelos governadores e prefeitos com diferentes abrangências e duração.

${ }^{1}$ O Comitê de Emergência do RSI para COVID-19 realizou sua primeira reunião em 22 de janeiro de 2020. No dia 30, o Diretor-Geral declarou que o surto constituía uma Emergência de Saúde Pública de Preocupação Internacional e emitiu Recomendações Temporárias do RSI. Iinformações: https://www.who.int/groups/covid-19-ihr-emergency-committee. Acesso em 26 março de 2021.

${ }^{2}$ Informações sobre os registros de casos que embasaram a tomada de decisão pela OMS, constam na transcrição da declaração de surto e emergência sanitária. Disponível em: https://www.who.int/director-general/speeches/detail/who-director-general-s-statement-on-ihremergency-committee-on-novel-coronavirus-(2019-ncov). Acesso em 26 março de 2021.

Revista Devir Educação, Lavras-MG. Edição Especial, p.341-362, Set./2021. 
No Estado de Santa Catarina, com a emissão do decreto estadual $n^{\circ}$ 515, em 17 de março de 2020, foram adotadas medidas de isolamento social por 30 dias, que impuseram a interrupção de atividades comerciais, industriais, educacionais, transporte coletivo e de cargas. Por este ato foram proibidas também as reuniões presenciais em eventos sociais, religiosos, atividades esportivas e do setor educacional, com exceção das atividades essenciais na saúde e assistência social, por exemplo

As estratégias da governança para implementar o isolamento social e mitigar o risco de infecção causada pela COVID-19, impactaram diretamente nas atividades educacionais. A educação não passou ilesa por este episódio. Então, como estabelecer novas rotinas pedagógicas e assegurar a oferta de atividades educacionais nos diversos níveis e modalidades? Nesta direção aborda-se as diretrizes de enfrentamento da pandemia, a partir de março de 2020.

\section{Encaminhamentos do Sistema de Educação Brasileiro diante da Pandemia}

A pandemia que assolou o território nacional impactou diversos segmentos da sociedade, exigindo novas formas de agir. Portanto, uma das principais inquietudes dos sistemas de ensino com a paralização das atividades nas unidades escolares incidiu no cumprimento do Art. 206 da Constituição Federal brasileira de 1988, o qual define que o ensino deve ser ministrado considerando o princípio da igualdade de condições para o acesso e permanência na escola e a garantia de padrão de qualidade. Porém, a Lei de Diretrizes e Bases da Educação Nacional, lei federal no 9.394/1996, não previa excepcionalidade para a oferta de ensino na modalidade remota para a educação infantil, diferentemente do ensino fundamental e, o $\S 4^{\circ}$, inciso IV, do Art. 32, cita que "O ensino fundamental será presencial, sendo o ensino a distância utilizado como complementação da aprendizagem ou em situações emergenciais." Essa lei prevê o cumprimento de 800 horas de trabalho pedagógico distribuídas em 200 dias letivos anuais.

O Art. 80 da lei federal n 9.394/1996 preconiza que “O Poder Público incentivará o desenvolvimento e a veiculação de programas de ensino a distância, em todos os níveis e modalidades de ensino, e de educação continuada", mas com a pandemia ocorreu a regulamentação deste artigo contemplando apenas o ensino superior, não se estendendo aos demais níveis e modalidades educacionais.

Revista Devir Educação, Lavras-MG. Edição Especial, p.341-362, Set./2021. 
Com o vácuo jurídico e após questionamentos, o Conselho Nacional de Educação (CNE) emitiu o Parecer CNE/CP n 5/2020 em 28 de abril de 2020, orientando quanto aos direitos e objetivos de aprendizagem, com sugestões de atividades utilizando-se as Tecnologias Digitais da Informação e Comunicação (TDIC), as possibilidades de mudanças no calendário escolar e o cômputo de atividades não presenciais para fins de cumprimento da carga horária mínima anual, em razão da pandemia da COVID-19.

Embora fosse o início da pandemia havia dúvidas quanto ao calendário escolar e o parecer indicou a "[...] dificuldade para reposição de forma presencial da integralidade das aulas suspensas ao final do período de emergência, com o comprometimento ainda do calendário escolar de 2021 e, eventualmente, também de 2022;” (BRASIL, 2020). Esse Parecer do CNE não avançou nas considerações sobre o cumprimento das 800 horas anuais e 200 dos dias letivos, pois estes deveriam ser contemplados em lei. Para tal, havia a necessidade de que o Congresso Nacional aprovasse legislação flexibilizando esse cumprimento.

Em 18 de agosto de 2020, a lei federal $n^{\text {a }} 14.040$ estabeleceu normas educacionais excepcionais a serem adotadas durante o estado de calamidade pública: os 200 dias letivos estavam dispensados de cumprimento pela educação infantil e pelo ensino fundamental, contudo caberia ao ensino fundamental manter 800 horas de atividades pedagógicas. Delegouse aos sistemas de ensino, inclusive os sistemas municipais, autonomia para deliberarem sobre a adoção de atividades pedagógicas não presenciais mediante a utilização de recursos tecnológicos digitais de informação e comunicação. O parágrafo $5^{\circ}$, inciso II, do Art. $2^{\circ}$ da lei federal $n^{\circ}$ 14.040/2020 dispôs sobre o compromisso dos sistemas de ensino que ao adotarem esse procedimento de ensino deveriam “[...] assegurar em suas normas que os alunos e os professores tenham acesso aos meios necessários para a realização dessas atividades" (BRASIL, 2020).

O município de Canoinhas possui sistema próprio de ensino, criado pela lei municipal $\mathrm{n}^{\text {o }} 2.920$ de 02 de dezembro de 1997 e da lei $\mathrm{n}^{\mathrm{o}}$ 4.851, de 14 de novembro de 2011. Esse sistema compreende escolas públicas de ensino fundamental da rede municipal de ensino, que oferecem a modalidade regular, educação de jovens e adultos, educação especial e aeducação no campo; os centros de educação infantil públicos; as instituições de educação infantil da iniciativa privada e os órgãos municipais da Secretaria Municipal de Educação, como o 
Conselho Municipal de Educação, o Conselho Municipal de Alimentação Escolar e o Conselho Municipal do Fundo de Manutenção e Desenvolvimento da Educação Básica e de Valorização dos Trabalhadores da Educação (FUNDEB). A esse sistema de ensino municipal foi conferido autonomia na tomada de decisões, desde que observada a Lei de Diretrizes e Bases da Educação Nacional (LDBN, 1996) e Pareceres do Conselho Nacional de Educação.

\section{Os Desafios e Reordenamentos do Ensino Fundamental Municipal em Canoinhas-SC}

O município de Canoinhas localiza-se no Planalto Norte do estado de Santa Catarina, foi criado pela lei estadual no 907 de 12 de setembro de 1911 e tem uma população estimada (2020) de 54.480 habitantes.

Em Canoinhas a rede pública municipal oferece educação infantil (creche e préescola) e o ensino fundamental com 23 unidades escolares e 3.711 estudantes matriculados. Nos 16 Centros de Educação infantil havia 2.472 estudantes totalizando 6.183 matrículas. Ou seja, é $47 \%$ do total dos estudantes de 0 a 17 anos matriculados em todas as redes do município (Sinopse Estatística da Educação Básica, publicada pelo Instituto Nacional de Estudos e Pesquisas Educacionais (INEP) em 2020). Quanto aos docentes da rede municipal de ensino, haviam deles 99 atuando nas creches, 108 docentes na pré-escola e mais de 230 docentes atuando nos anos iniciai e anos finais, educação especial e educação de jovens e adultos.

A partir do entendimento de que a crise sanitária gerava a necessidade de implementação de ações diferenciadas das clássicas e andamento, havia a insegurança jurídica quanto ao respaldo das iniciativas, o que poderia comprometer o reconhecimento de atividades educacionais como processo de ensino-aprendizagem no ano letivo de 2020. Entendeu-se que esta situação era comum também em outros municípios brasileiros, além de Canoinhas. Era consenso de que os sistemas municipais de ensino deveriam assegurar o direito humano à educação em quaisquer circunstâncias e contextos.

Para avançar nos debates sobre alternativas viáveis nesse enfrentamento, a Federação Catarinense de Associações de Municípios (FECAM) liderou reflexões sobre estratégias que atendessem minimamente a perspectiva dos objetivos da aprendizagem, da segurança nutricional e da manutenção do vínculo dos estudantes com o meio escolar. Efetivou o 


\section{OO DEVIR EDUCAÇÃO}

ISSN: 2526-849X

assessoramento ao Colegiado Regional de Secretários de Educação, dos técnicos da Educação e do Colegiado das Nutricionistas da Alimentação Escolar.

Mesmo antes da aprovação da lei federal nº 14.040 de 2020, o Conselho Municipal de Educação de Canoinhas (CMEC) havia aprovado a Resolução 002/CME/2020, em 07 de abril de 2020 que estabeleceu normas e orientações sobre o Regime Especial de Atividades de Aprendizagem Não Presenciais para o Sistema Municipal de Ensino de Canoinhas. Para fins de cumprimento do calendário letivo do ano de 2020, em consonância com a prevenção da contaminação pela doença da COVID-19 e sob respaldo nessa Resolução do CME, a Secretaria Municipal de Educação implementou um conjunto de ações para atender os estudantes matriculados na rede pública municipal de ensino.

Com a suspensão das atividades educacionais presenciais por um período de sessenta dias no município de Canoinhas, a Secretaria Municipal de Educação priorizou a destinação da alimentação escolar. Em março de 2020 as 44 unidades educacionais haviam sido abastecidas com a alimentação para os estudantes (inclusive gêneros perecíveis). Para evitar perdas desses alimentos foi autorizada pela gestão municipal, por meio de $\operatorname{decreto}^{3}$, a distribuição imediata dos gêneros alimentícios à rede de acolhimento institucional municipal e às famílias de estudantes, considerando o critério da situação de vulnerabilidade financeira.

A gestão e as equipes de profissionais do sistema municipal de ensino identificaram que a implementação de atividades educacionais e pedagógicas não presenciais poderia ser inviabilizada se o acesso dos estudantes às TDIC fosse restrito. Entre as dificuldades havia a estrutura disponível em cada uma das 44 unidades educacionais, principalmente na infraestrutura das escolas de educação no campo. Outra dificuldade estava relacionada à distância da residência dos estudantes matriculados nas unidades educacionais municipais no meio rural, pois havia famílias que residiam até 85 quilômetros distantes da sede do município e sem acesso às TIC.

As questões se avolumavam e entre estas estava posta a necessidade de identificar as possibilidades de atividades pedagógicas que assegurassem o ensino tanto na educação infantil como no ensino fundamental. Mas, como a estrutura disponível serviria para que o acesso às atividades fosse efetivo para todos os estudantes? Quais os formatos de ensino

\footnotetext{
${ }^{3}$ Lei municipal n. 6240 de 18 e março de 2020, autorizou a doação de alimentos perecíveis e semi perecíveis das Escolas e Centros de Educação Infantil da Rede Municipal de Ensino de Canoinhas aos estudantes que fossem comprovadamente, de baixa renda.
}

Revista Devir Educação, Lavras-MG. Edição Especial, p.341-362, Set./2021. 


\section{ODEVIR EDUCAÇÃO \\ ISSN: 2526-849X}

poderiam atender os estudantes de forma equitativa? A implementação de uma nova modalidade de ensino asseguraria aos profissionais de educação uma situação de segurança em relação às recomendações sanitárias de prevenção à Covid-19?

Além da segurança sanitária, a formação continuada dos profissionais do magistério e da educação teria que ser priorizada. Iniciou-se levantamento sobre as ferramentas disponíveis para instrumentalizar os profissionais de educação na rede pública municipal de ensino para a implementação da modalidade do ensino remoto.

As respostas a essas indagações foram resultado das discussões entre os gestores e as equipes técnicas da Secretaria Municipal de Educação que pautava a continuidade do ano letivo com aulas remotas, o que demandou um levantamento sobre o perfil das famílias dos estudantes. Foi elaborado um formulário, Google Forms, que identificou o acesso à computadores, tablets, celulares, rede de dados móveis e rede mundial de computadores. Dentre os $6.282^{4}$ estudantes matriculados, cerca de metade das famílias respondeu ao questionário e entendeu-se que seriam estes os estudantes que teriam, mesmo que minimamente, acesso a alguma tecnologia de informação.

Concomitante ao formulário distribuído às famílias, o setor de tecnologias de informação (TI) da Secretaria Municipal de Educação, realizou levantamento de possibilidades de plataformas educacionais para a implantação, monitoramento e acompanhamento on-line que permitissem atividades pedagógicas não presenciais.

O setor pedagógico da Secretaria organizou um grupo de trabalho que realizou estudos sobre o embasamento legal e fundamentação teórica que viabilizassem a implementação de atividades não presenciais para os estudantes com e sem acesso às plataformas virtuais digitais educacionais. Havia preocupação com a implementação da Proposta Curricular de Educação Básica das Redes Municipais de ensino na região da AMPLANORTE, iniciada em 2019 e que deveria ser efetivada durante o ano letivo de 2020, com a necessidade de assegurar oitocentas horas de trabalho pedagógico. Era necessário agilizar as alternativas de ensino não presencial, para que fossem regulamentadas e se retomar o ano letivo para cumprimento do calendário escolar e as horas de trabalho pedagógico regulamentado.

Questões quanto a formação dos professores também passaram a fomentar as decisões. O risco de infecção acabou por impor aos professores, obrigatoriamente, a mudanças nas suas

\footnotetext{
${ }^{4}$ Informações do movimento de matrículas da Rede Municipal de Educação, Secretaria Municipal de Educação, fevereiro de 2020.
}

Revista Devir Educação, Lavras-MG. Edição Especial, p.341-362, Set./2021. 


\section{OD DEVIR EDUCAÇÃO}

ISSN: 2526-849X

rotinas de trabalho, com o uso das tecnologias de informação como um instrumento essencial para o processo de ensino e aprendizagem.

O isolamento social compeliu a Secretaria Municipal de Educação a preocupar-se com a formação do professor e dos demais profissionais da rede municipal de ensino, com a necessidade de viabilizar o seu acesso a equipamentos, rede mundial de computadores e tecnologias digitais. Além da preocupação com a segurança e a saúde dos professores e de sua família: dever-se-ia seguir as recomendações sanitárias de isolamento social.

Surge a necessidade de se estabelecer a conexão destes profissionais e o novo formato de interação virtual. A estrutura particular do profissional de educação faria a diferença na prática educadora no desenvolvimento de atividades de ensino e aprendizagem. Então quais seriam as ferramentas disponíveis para instrumentalizar os profissionais do magistério e que permitisse a rede municipal de ensino instituir a modalidade de ensino remoto?

Aos gestores das unidades educacionais coube realizar um levantamento preliminar sobre o acesso dos professores às tecnologias e a rede mundial de computadores (internet) para que disponibilizasse o suporte, com o apoio dos instrutores de informática e de acordo com a estrutura disponível na unidade educacional, criando-se condições de acesso e permitindo que o vínculo entre o professor e os estudantes fosse retomado o mais breve possível.

Além da disponibilização do suporte e da estrutura, a efetivação do ensino remoto demandaria que os professores recebessem formação para manuseio das Tecnologias de Informação (TIC) como ponto essencial para a implantação desta metodologia de ensino.

O Conselho Municipal de Educação (CME), em abril de 2020, havia emitido a Resolução 002/2020, com Normas e Orientações sobre o Regime Especial de Atividades de Aprendizagem Não Presenciais para o Sistema Municipal de Ensino de Canoinhas, fruto da discussão conjunta da equipe da Secretaria de Educação. As atividades de aprendizagem não presenciais, foram caracterizadas como ações pedagógicas não presenciais, considerando a interação entre o professor da turma ou do componente curricular, com o estudante por meio de orientações impressas, estudos dirigidos, plataformas virtuais, correio eletrônico, redes sociais, chats, fóruns, diários eletrônicos, vídeoaulas, áudio-chamadas, vídeo chamadas e outras assemelhadas. (CME, Resolução 002/2020).

Ainda em abril de 2020, um grupo de trabalho e estudos formado pela equipe pedagógica da Secretaria Municipal de Educação, das unidades educacionais e pelos gestores 
passou a dedicar-se à construção do Plano Emergencial para o Regime de Atividades de Aprendizagem Não Presencial. O documento foi elaborado com o objetivo de estabelecer diretrizes para o período de atividades não presenciais, o qual foi atualizado sistematicamente conforme o contexto da pandemia e de acordo com novas regulamentações.

Para a construção desse plano foram consideradas as orientações do Tribunal de Contas do Estado (TCE) e Ministério Público (MP) de Santa Catarina as quais, enfatizaram a necessidade de que as redes de ensino desenvolvessem estratégias para atenção aos estudantes em contextos socioeconômicos mais vulneráveis, que não possuíam acesso à rede mundial de computadores ou outros equipamentos que viabilizassem o aprendizado. Foi ressaltado por essas instituições, que as redes de ensino deveriam manter atenção redobrada ao abandono e à evasão escolar, identificando dificuldades de acesso às aulas remotas, a atenuação do vínculo com a escola e eventuais dificuldades de organização da dinâmica familiar impostas pelo risco de infecção pela COVID-19.

Desta forma, foram implantadas estratégias e ações em conjunto com os pedagogos, os orientadores educacionais e assistentes sociais do setor de serviço social ao educando para combater o abandono escolar na rede municipal de ensino de Canoinhas. Estas ações de busca ativa consistiam no monitoramento e averiguação das situações envolvendo os estudantes das creches até as turmas de Educação de Jovens e Adultos e ocorreu de forma virtual, a partir da matrícula, controle da entrega de material impresso e frequência nas aulas remotas. Para o registro dos casos de abandono da escola era preenchido o Formulário de Busca Ativa, desenvolvido pelo Ministério Público de Santa Catarina no ambiente virtual Google Forms, o que implicou em maior agilidade nos encaminhamentos realizados e articulou as escolas, o Conselho Tutelar e o próprio Ministério Público.

Durante todo o período de atividades não presenciais, no ano letivo de 2020, a Rede Municipal de Educação de Canoinhas registrou 20 casos de abandono sem resolutividade. Outros casos de infrequência foram identificados, mas com as intervenções das equipes pedagógicas ou do Conselho Tutelar, os estudantes retornaram às atividades.

Simultaneamente e regionalmente (AMPLANORTE), foram discutidas as problemáticas pertinentes à alimentação escolar. Havia entendimento de que a alimentação enquanto direito social deveria estar assegurada por políticas e ações que garantissem a segurança alimentar e nutricional mesmo com a suspensão das aulas.

Revista Devir Educação, Lavras-MG. Edição Especial, p.341-362, Set./2021. 
Havia a necessidade de manutenção do Programa Nacional de Alimentação Escolar (PNAE), tendo em vista as implicações da aquisição de alimentos do Programa de Aquisição de Alimentos (PAA) e os encaminhamentos necessários para doação dos alimentos que já estavam estocados nos depósitos das unidades educacionais. Nessa direção, foi criada uma Comissão Intersetorial de Alimentação Escolar (CIAE) para acompanhar as doações dos estoques das unidades educacionais, definir critérios de seleção de famílias dos estudantes que receberiam as doações e para acompanhar a organização dos chamados kits ${ }^{5}$ para que atendessem as recomendações nutricionais mínimas dos estudantes. A CIAE de Canoinhas foi articulada pelo setor de alimentação escolar e serviço social ao educando e envolveu o Ministério Público, a Defesa Civil, o Conselho Municipal de Direitos da Criança e do Adolescente, a Secretaria Municipal de Assistência Social e o Programa de Segurança Alimentar.

Um levantamento realizado pelas equipes administrativas, apontou que os estoques das unidades educacionais não seriam suficientes para atender minimamente a todos os estudantes. Assim, a CIAE deliberou que a doação de gêneros alimentícios fosse entregue para os estudantes das famílias beneficiárias do Programa Bolsa Família (PBF). A entrega ocorreu no mês de maio de 2020 e foram distribuídos 1.398 kits de alimentos pela rede municipal de ensino. No mês de outubro de 2020, foram distribuídos 5.409 kits com investimento de $\mathrm{R} \$ 568.193,80$ e em novembro e dezembro ocorreu a entrega de 5.829 kits equivalentes a $\mathrm{R} \$ 265.118,49$.

A pandemia se apresentou aos gestores municipais como uma ameaça relacionada aos recursos humanos, ou seja, como manter o pagamento do salário e remuneração dos trabalhadores, servidores efetivos e contratados, se a paralização das atividades traria impacto e provável queda na arrecadação no município? Intervir nos gastos, com o corte de vagas ou a suspensão dos contratos contribuiria para a formação de uma legião de desempregados e iria sujeitá-los à vulnerabilidade social.

Para que o impacto da provável queda da arrecadação repercutisse sobre os trabalhadores da educação, coube ao setor de recursos humanos da Secretaria Municipal de

\footnotetext{
"Kit" foi um termo utilizado na legislação concernente à forma de organização e distribuição dos gêneros alimentícios da alimentação escolar durante a pandemia, pelas redes municipais e estadual de ensino. A justificativa para o uso deste termo foi a de que havia a preocupação que não fossem utilizados termos relacionados ao benefício eventual da política de assistência social: o sacolão ou a cesta básica.
}

Revista Devir Educação, Lavras-MG. Edição Especial, p.341-362, Set./2021. 
Educação (SME) juntamente com o setor pedagógico, o redimensionamento das atribuições dos profissionais com a finalidade de manter e justificar o contrato de trabalho e permitindo suporte para outras áreas de enfrentamento à infecção pela COVID-19.

Foram revistas e justificadas as atribuições dos monitores de educação infantil, cerca de 53, que antes da paralização das atividades presenciais nas unidades educacionais, exerciam cuidados às crianças de 4 meses a 3 anos nas creches. Estes passaram a atuar na orientação sobre cuidados e práticas de higiene para prevenção da infecção pela COVID-19 nas barreiras sanitárias, distribuição de máscaras faciais e de folhetos informativos em domicílio. Os professores foram mantidos em suas funções e as equipes pedagógicas (pedagogos e orientadores educacionais) foram envolvidos no planejamento das atividades não presenciais. Os monitores de educação especial se dedicaram ao ajuste das atividades pedagógicas para atender os estudantes com deficiência.

Os profissionais que integravam o Programa Espaço Crescer, concebido para atender estudantes da rede municipal de ensino que apresentavam dificuldades de aprendizagem teve sua equipe multidisciplinar (fonoaudiólogo, psicólogos), remanejada emergencial e temporariamente para atuação na Secretaria Municipal de Saúde integrando as equipes de monitoramento de pacientes com suspeita ou confirmação da infecção pela COVID-19.

Com relação aos professores, a estratégia de implementar o ensino na modalidade não presencial apresentou a necessidade de oportunizar capacitações para que pudessem desenvolver as suas atividades educacionais de modo a minimizar os impactos no processo de ensino e aprendizagem dos estudantes. Mas estes também necessitavam de inclusão digital como acesso; alfabetização digital; e apropriação de tecnologias (MORI, 2011).

\section{Formação de professores e profissionais de educação para ensino não presencial}

Durante a suspensão das atividades presenciais na rede pública municipal de ensino, de março a dezembro de 2020, foi prioridade a viabilização da implementação imediata de atividades de aprendizagem não presenciais. Pode-se considerar nessa implementação uma mudança abrupta das práticas pedagógicas, que confirmou que os sujeitos são capazes de repensar e agir frente processos de mudanças intervir nas transformações no mundo e com o mundo (FREIRE, 1996).

Revista Devir Educação, Lavras-MG. Edição Especial, p.341-362, Set./2021. 
Para que fossem retomadas as atividades educacionais, um grupo de trabalho se dispôs a organizar atividades, imediatamente após suspenção das atividades escolares presenciais. Em 01 abril de 2020 foi disponibilizado no sítio ${ }^{6}$ institucional da Secretaria Municipal de Educação, para estudantes com acesso à rede mundial de computadores, atividades pedagógicas e informações sobre a prevenção do contágio da COVID-19.

A próxima etapa envolveu levantamentos e discussões entre o grupo de trabalho e o setor de tecnologias de informação, para que se viabilizassem as atividades pedagógicas não presenciais, em um formato seguro, com acesso garantido, facilitado e contínuo, concretizando o ensino remoto.

Foi consenso para o grupo de trabalho que a alternativa mais viável seria a disponibilização de uma plataforma virtual de interação educacional, consideradas diversas determinantes como a interrupção do transporte escolar e do transporte coletivo que impedia a presença dos professores nas unidades educacionais. Foi considerada neste contexto pandêmico, a importância de se manter o vínculo fortalecido com os estudantes e a necessidade de utilização de estratégias pedagógicas além das tradicionais atividades impressas.

Coube aos profissionais de educação providenciar condições, em suas residências, para o acesso à rede de computadores e às tecnologias digitais de informação e comunicação para a implementação das atividades de aprendizagem não presenciais.

Esta disponibilidade dos docentes em providenciar meios para o acesso on line marcou a retomada das atividades de aprendizagem não presenciais, como compromisso coletivo na construção de trabalho colaborativo. Um exemplo positivo de superação às dificuldades que demonstrou aos estudantes e às suas famílias que o cenário pandêmico não impediria a continuidade das atividades da educação.

Na busca por uma plataforma virtual educacional, o setor de TI da Secretaria Municipal de Educação articulou cooperação com a Google que, enquanto uma empresa que desenvolvera uma plataforma virtual de recursos de ensino, que disponibilizou, colaborativamente, sem custos para a prefeitura municipal, o Google Sala de Aula.

Mas para o uso de tal recurso, o professor, protagonista do fazer pedagógico, precisaria participar de formação que abordasse a utilização dos recursos oferecidos pela

${ }^{6}$ Endereço do sítio institucional da Secretaria Municipal de Educação (SME): www.sme.pmc.sc.gov.br.

Revista Devir Educação, Lavras-MG. Edição Especial, p.341-362, Set./2021. 
plataforma virtual Google. Assim, a SME estabeleceu cooperação com o Serviço Nacional de Aprendizagem Industrial (SENAI) que realizou curso com 10 horas aulas, sobre as ferramentas e recursos disponíveis na plataforma.

Quadro 1 - Assuntos abordados na formação de docentes da rede municipal de ensino de Canoinhas - maio 2020

\begin{tabular}{|c|c|}
\hline Data & Assunto \\
\hline $05 / 05 / 2020$ & Google Drive \\
\hline $08 / 05 / 2020$ & Gmail, Google Keep, Google Documentos \\
\hline $13 / 05 / 2020$ & Screencastfy, Google Formulários, Google Apresentações \\
\hline $15 / 05 / 2020$ & Google Sala de Aula, Google Agenda, Google Meet, YouTube \\
\hline
\end{tabular}

Fonte: SME, Canoinhas, 2021

Essa cooperação entre a SME e o SENAI permitiu que os professores pudessem utilizar as ferramentas da plataforma com interação entre o professor e estudantes, em tempo real, assim como a troca de atividades complementares e avaliativas.

Imediatamente foi providenciado suporte aos professores e equipes pedagógicas, pelos Instrutores de Informática que estiveram disponíveis nas escolas e promoveram o assessoramento dos professores e estudantes para o uso de aplicativos de troca de mensagens, e-mails, programas de gravação e edição de vídeos e imagens.

Concomitante a implantação do ambiente virtual, iniciou-se em 04 de maio de 2020, a distribuição de materiais impressos para os estudantes. As unidades educacionais abriram suas portas, receberam estudantes e familiares para a entrega de atividades impressas, oportunizando acesso ao processo de aprendizagem a estudantes sem acesso a conteúdos de forma on line.

Os materiais impressos foram disponibilizados continuamente, organizados em ciclos quinzenais e que poderiam ser retirados nas unidades educacionais, ou no equipamento social mais próximo das moradias dos estudantes como capelas, associações de moradores e salões de festas como ocorreu em algumas localidades no meio rural de Canoinhas.

Destaca-se que a equipe pedagógica teve a preocupação com os documentos para o registro das atividades desenvolvidas pelos estudantes nesse período. Assim, elaboraram uma planilha sobre o envio do material, na qual foi discriminada a forma de entrega das atividades aos estudantes, se pela plataforma virtual, formato impresso, por aplicativo de mensagens instantâneas WhatsApp, tornando possível acompanhar e monitorar as atividades, bem como 
continuar com a busca ativa quando era identificada ausência do estudante nas atividades escolares.

Desde que foi decretado o estado da pandemia, surgiram inseguranças, ameaças e riscos eminentes à vida que impactaram as pessoas tanto pelo isolamento social quanto pelas preocupações sobre as questões econômicas e as dificuldades de manutenção da renda. Este contexto sem perpectivas positivas fez com que o contato do estudante com o professor mesmo que por meio das TDIC trouxesse aos estudantes algum acolhimento. Mesmo sob a égide de um eminente risco de contágio, os profissionais de educação não mediram esforços, para superar barreiras e limites acolhendo todos, estudantes e familiares.

Os professores passaram a aproximar-se cada vez mais das TDIC principalmente quando viram a repercussão positiva do acolhimento que puderam oferecer aos estudantes em tempos pandêmicos. O uso das tecnologias não é fato novo na área educacional, mas as tradições e as resistências justificaram o retardamento da utilização de novas formas de interagir, de ensinar, de aprender e de conviver. Como expõem Silva, Campelo e Borges (2021, p.04) “[...] uma boa formação inicial de professores deve preparar para o uso das TIC em sala de aula, pois professores bem formados conseguem ter segurança para administrar a diversidade de alunos, garantindo bom aproveitamento da experiência de cada um [...]".

Mesmo com a atualização dos professores em termos de teorias e práticas pedagógicas, deveria ocorrer a inclusão desde a formação inicial, para romper o ciclo de resistência, o uso de aportes tecnológicos. Como afirmam Lopes e Fürkotter (2016) sobre a formação inicial dos professores e o currículo acadêmico das instituições de ensino superior que considerem o uso das TDIC, que no contexto atual não há evidências de que esta formação é efetivamente implementada aumentando a distância entre o professor e o perfil do estudante que se apresenta no ensino institucionalizado.

Mesmo com as resistências ou escassas na formação de professores de uso de TDIC para as práticas docentes, não havia outra alternativa possível mo contexto da pandemia a não ser utilizar as tecnologias no cotidiano educacional. Mesmo sem o tempo e o investimento suficiente no aperfeiçoamento dos docentes, a utilização das TDIC teve que ser incorporada obrigatoriamente.

A equipe pedagógica da Secretaria Municipal de Educação organizou e auxiliou os grupos de trabalho que se dedicaram ao planejamento das atividades para as turmas da educação infantil e dos anos iniciais, que no primeiro ciclo foi unificado. O planejamento das 
atividades para os anos finais e educação de jovens e adultos, foi organizado de acordo com cada um dos componentes curriculares.

Estavam contempladas nas atividades não presenciais todas as etapas de ensino, desde o ensino fundamental até a educação de jovens e adultos, porém, a regulamentação autorizando as atividades pedagógicas não presenciais para a educação infantil, ocorreu apenas em agosto com a publicação da lei federal $n^{\circ}$ 14.040, 18 de agosto de 2020. Para os estudantes matriculados nas creches, as atividades eram enviadas aos pais e responsáveis, oferecendo exercícios de estímulo ao desenvolvimento infantil e vídeos de curta duração, filmados pelo professor com o objetivo de manter esse vínculo.

O compromisso da Secretaria Municipal de Educação em aproximar-se dos profissionais realizando encontros virtuais, ocorreram tanto no início da pandemia como na implantação das atividades não presenciais e ao longo do ano de 2020. As primeiras reuniões virtuais foram organizadas considerando grupos de professores por níveis e etapas de ensino, o que oportunizou a abordagem de temas relacionados a crise sanitária, as políticas municipais emergenciais de saúde, assistência social, segurança alimentar, defesa civil e encaminhamentos da política municipal de educação. Ocorreram reuniões virtuais com cada unidade educacional e a equipe pedagógica da SME, com o objetivo de debater dificuldades pontuais e o alinhamento da equipe pedagógica.

Um obstáculo enfrentado ocorreu na organização da formação continuada que considerasse todos os profissionais da Rede Pública Municipal de Ensino. Em resposta, foram estabelecidas colaborações com instituições de ensino superior que disponibilizaram pesquisadores e especialistas de diversas áreas do conhecimento para debater temas relacionados a pandemia COVID-19 e as atividades educacionais, em Ciclos de Webinares. O primeiro ciclo ocorreu no período de 30 de julho a 27 de agosto e o segundo ciclo, entre 03 de setembro e 22 de outubro e foram transmitidas ao vivo por canal de transmissão de vídeos, o You Tube que proporcionou o acesso às webinares tanto pelos profissionais da Rede Pública Municipal de Ensino, rede privada e profissionais da educação dos municípios da região na qual se situa Canoinhas.

No ano de 2020, a distância entre a escola e os estudantes exigiu outras formas de ensinar em meio a uma crise sanitária marcada pela impossibilidade da interação presencial entre estudantes e professores. “[...] ao realizar a ação pedagógica e curricular nas interações educativas, os professores e os estudantes experimentaram os atravessamentos das condições 
objetivas e subjetivas existentes, que produziram diferentes graus de realização da aprendizagem" (UBES, 2021, p.5). As metodologias de ensino e as formas de avaliação dos estudantes foram remodeladas. Nesse sentido, a equipe pedagógica da SME realizou estudos que foram regulamentados pelo CME por meio da Resolução 005/SME/2020. As equipes pedagógicas foram orientadas sobre a importância do preenchimento de fichas de acompanhamento dos estudantes de acordo com as competências e habilidades desenvolvidas, bem como a aplicação de autoavaliações e questionários enviados aos pais ou responsáveis.

Acompanhando a consolidação do planejamento e execução das atividades pedagógicas em ambientes virtuais, os profissionais envolvidos no apoio educacional redimensionaram suas atividades. A exemplo do Programa de Atenção à Educação Municipal $(\mathrm{PAEM})^{7}$, o Espaço Crescer retornou suas finalidades e estabeleceu um plano de ação emergencial com estratégias de orientação aos profissionais da educação com o objetivo de reduzir o impacto psicológico e social motivado pelo longo período de isolamento social e da ausência de atividades presenciais nas unidades escolares.

No último bimestre de 2020, com vistas a regrar o retorno às atividades educacionais foi emitido o Plano de Contingência Escolar (PLANCON-EDU/ESCOLAR) municipal, aprovado em outubro de 2020, o qual apontou as diretrizes para o retorno do funcionamento das unidades educacionais de qualquer modalidade de ensino. Nesse Plano foram previstos os protocolos que deveriam ser executados e a adequação das estruturas para que estivesse garantida a segurança sanitária no retorno às atividades educacionais presenciais.

A partir do PLANCON-EDU/ESCOLAR municipal, cada uma das unidades educacionais do município, considerando suas especificidades estruturais e necessidades de protocolo elaborou seu PLANCON, que foi analisado e homologado pelo Comitê Municipal de Gerenciamento da Pandemia da COVID-19.

\section{Considerações Finais}

\footnotetext{
${ }^{7}$ No ano de 2019 o Espaço Crescer realizou 247 atendimentos de psicologia e 120 de fonoaudiologia, houveram também atendimentos com intervenção das assistentes sociais, para estudantes que apresentavam dificuldades de aprendizado das unidades educacionais na rede municipal de ensino. Fonte: Relatório Anual de registros dos atendimentos, 2019.
} 
Quando uma sociedade se depara com um cenário de crise sanitária no qual as incertezas se estenderam por um longo período, esta espera uma rápida resposta do Estado. Os governantes e a equipe técnica da SME, ao mesmo tempo que atuaram na problemática causada pela pandemia, consideraram uma proposta de organização pedagógica para implementar assim que fosse possível o retorno às atividades educacionais presenciais. Para que esse retorno pudesse ocorrer foi determinante que fossem mantidos os vínculos entre os professores, a escola e os estudantes.

A atuação conjunta do Conselho Municipal de Educação de Canoinhas, comprometido com o regramento que tornasse a experiência pedagógica de interação virtual possível, com prejuízo mínimo no aprendizado, tornou esta experiência referência regional, tanto pela regulamentação e convalidação das atividades educacionais não presenciais como no redimensionamento do calendário escolar para cumprimento do ano letivo.

A mobilização célere de grupos de estudo para cada frente de trabalho: atividades pedagógicas da plataforma virtual de aprendizagem e para o material impresso, alimentação escolar, saúde mental, atendimento socioeducativo, prevenção contra infecção pela COVID19, busca ativa, educação especial e de especialistas da educação, poderão ser consideradas decisões que marcaram o período entre março a agosto de 2020.

Os tempos pandêmicos trouxeram à tona emergências imprimindo agilidade à política pública, que muitas vezes parece morosa, mas respondeu rapidamente consolidando ações, demonstrando que há como reorganizar, refazer, respeitar o direito social à educação e priorizar o interesse dos estudantes em especial das crianças e dos adolescentes.

\section{Referências}

BRASIL. Lei n.9.394/96. Lei de Diretrizes e Bases da Educação Nacional. Disponível em: http://www.planalto.gov.br/ccivil_03/leis/19394.htm. Acesso em 28 março. 2021.

BRASIL. Instituto Nacional de Estudos e Pesquisas Educacionais Anísio Teixeira. Censo da Educação Básica: Sinopse Estatística da Educação Básica - 2020. Disponível em: https://www.gov.br/inep/pt-br/acesso-a-informacao/dados-abertos/sinopsesestatisticas/educacao-basica. Acesso em 12 abril. 2021.

BRASIL. Portaria nº 188, Ministério da Saúde, 3 de fevereiro de 2020. Declara Emergência em Saúde Pública de importância Nacional (ESPIN) em decorrência da Infecção Humana pelo novo Coronavírus (2019-nCoV). Diário Oficial da União. Disponível em: https://www.in.gov.br/en/web/dou/-/portaria-n-188-de-3-de-fevereiro-de-2020-241408388. Acesso em 26 março. 2021. 
BRASIL. Decreto Legislativo no 6, de 2020, reconhece a ocorrência do estado de calamidade pública, nos termos da solicitação do Presidente da República. Diário Oficial da União. Disponível em: http://www.planalto.gov.br/ccivil_03/portaria/DLG6-2020.htm. Acesso em 25 março. 2021.

BRASIL. Medida provisória n. 934, $1^{\text {o }}$ de abril de 2020. Estabelece normas excepcionais sobre o ano letivo da educação básica e do ensino superior decorrentes das medidas para enfrentamento da situação de emergência de saúde pública de que trata a Lei $\mathrm{n}^{\circ} 13.979$, de 6 de fevereiro de 2020. Diário Oficial da União. Disponível em: https://www.in.gov.br/en/web/dou/-/medida-provisoria-n-934-de-1-de-abril-de-202025071059. Acesso em 28 março. 2021.

BRASIL. Parecer CNE/CP $\mathbf{n}^{\mathbf{0}} \mathbf{5 / 2 0 2 0}$, aprovado em 28 de abril de 2020. Orienta a reorganização do calendário escolar e da possibilidade de cômputo de atividades não presenciais para fins de cumprimento da carga horária mínima anual, em razão da Pandemia da COVID-19. Conselho Nacional de Educação, Ministério da Educação. Disponível em: http://portal.mec.gov.br/index.php. Acesso em 28 março. 2021.

BRASIL. Ministério da Saúde, Secretaria de Atenção à Saúde. Cadastro Nacional de Estabelecimentos de Saúde/CNESNet. Disponível em : http://cnes2.datasus.gov.br. Acesso em 15 maio. 2021.

BRASIL. Lei federal n. 14.040, de 18 de agosto de 2020. Estabelece normas educacionais excepcionais a serem adotadas durante o estado de calamidade pública e autoriza a oferta de atividades pedagógicas não presenciais para a educação infantil. Diário Oficial da União. Disponível em: https://www.in.gov.br/en/web/dou. Acesso em 15 maio. 2021.

CANOINHAS. Decreto municipal n. 58, de 17 março de 2020. Dispõe sobre as medidas para enfrentamento da emergência de saúde pública de importância internacional decorrente da infecção humana pelo novo coronavírus (covid-19) e dá outras providências. Diário Oficial dos Municípios. Disponível em: https://static.fecam.net.br/uploads/719/arquivos. Acesso em 17 maio. 2021.

CANOINHAS. Resolução SME n.001, de 28 de abril de 2020. Institui a Comissão Intersetorial de Alimentação Escolar. Diário Oficial dos Municípios, Secretaria Municipal de Educação. Disponível em: https://diariomunicipal.sc.gov.br. Acesso em 26 de março. 2021.

CANOINHAS. Resolução n. 002, 07 de abril de 2020. Estabelece normas de orientações sobre o regime especial de atividades de aprendizagem não presenciais para o sistema municipal de ensino de Canoinhas. Diário Oficial dos Municípios, Conselho Municipal de Educação.

Disponível

em: https://edicao.dom.sc.gov.br/pdfjs/web/viewer.html?file=https\%3A\%2F\%2Fedicao.dom.sc.go v.br\%2F2020\%2F04\%2F1586883370_edicao_3111_assinada.pdf\#page=278. Acesso em 28 março. 2021. 
CANOINHAS. Lei municipal n. 6.240. Autoriza a doação de alimentos e dá outras providências. Disponível em: https://www.pmc.sc.gov.br/legislacao/. Acesso em 12 abril. 2021.

FREIRE, Paulo. Pedagogia da Autonomia: saberes necessários à prática educativa.

11 ed. São Paulo: Paz e Terra, 1996. Disponível em: http://www.unirio.br/cla/ppgeac/processo-seletivo-2021/bibliografia-2021/freire-paulopedagogia-da-autonomia-saberes-necessarios-a-pratica-educativa/view. Acesso em 17 julho. 2021.

INSTITUTO BRASILEIRO DE GEOGRAFIA E ESTATÍSTICA. Panorama cidades. Disponível em: https://cidades.ibge.gov.br/brasil/sc/canoinhas/panorama. Acesso em: 15 maio. 2021.

LOPES, Rosemara Perpetua; FÜRKOTTER, Monica. Formação inicial de professores em tempos de TDIC: uma questão em aberto. Educação em Revista. 2016, v. 32, n. 4 , p. 269296. Disponível em: https://doi.org/10.1590/0102-4698150675. Acessado 26 agosto. 2021.

MORI, Cristina Kiomi. Políticas públicas para inclusão digital no Brasil: aspectos institucionais e efetividade em iniciativas federais de disseminação de telecentros no período 2000-2010. 2011. 351 f. Tese (Doutorado em Política Social) - Universidade de Brasília, Brasília, 2011. Disponível em: https://repositorio.unb.br/handle/10482/10560. Acesso em 30 junho. 2021

SANTA CATARINA. Decreto n. 515, de 17 de março de 2020. Declara situação de emergência em todo o território catarinense, nos termos do COBRADE $n^{\circ}$ 1.5.1.1.0 - doenças infecciosas virais, para fins de prevenção e enfrentamento à Covid-19, e estabelece outras providências. Florianópolis, Governo do Estado de Santa Catarina, Disponível em: https://www.sc.gov.br/images/Secom_Noticias/Documentos/. Acesso em 26 março. 2021.

SANTA CATARINA. Tribunal de Contas do Estado. Nota técnica CTE-IRB n 01/2020: Orientações aos gestores de Educação durante e após a pandemia de Covid-19. Florianópolis: TCE/SC- DAE, 2020. Disponível em: https://www.tcesc.tc.br/estudo-do-tcescapresenta-orientacoes-aos-gestores-municipais-de-educacao-em-funcao-do-periodo-da/. Acesso em 26 março. 2021.

SILVA, Maria Lúcia Ferreira da; CAMPELO, Calebe Lucas Feitosa; BORGES, Eli Linhares de Meneses. Tecnologias na Educação: perspectivas e desafios na formação de professores frente à pandemia do novo coronavírus. Revista Educação Pública, v. 21, nº 16. Disponível em: $\quad$ https://educacaopublica.cecierj.edu.br/artigos/21/16/tecnologias-na-educacaoperspectivas-e-desafios-na-formacao-de-professores-frente-a-pandemia-do-novo-coronavirus. Acesso em 4 maio. 2021.

UNIÃO BRASILEIRA DOS ESTUDANTES SECUNDARISTAS. Nota Técnica Direito humano à educação na pandemia: desafios, compromissos. São Paulo, Centro de Estudos e Memória da Juventude 2021. Disponível em: https://ubes.org.br/2021/ubes-lancadocumento-sobre-educacao-na-pandemia/. Acesso em 30 junho. 2021. 
Recebido em: 22/07/21

Aprovado em: 25/08/21

Revista Devir Educação, Lavras-MG. Edição Especial, p.341-362, Set./2021. 